\title{
Anti-dyslipidemic effect of zinc oxide nanoparticles against cyclophosphamide induced dyslipidemia in male albino rats
}

\author{
Karema El. M. Shkal ${ }^{1}$, Ahmed M. Attia ${ }^{2}$, Sabah G. El-Banna ${ }^{2}$, Azab Elsayed Azab ${ }^{3 *}$, and Rabia A. M. Yahya ${ }^{1}$ \\ ${ }^{1}$ Pharmacology Department, Faculty of Medicine, Sabratha University, Libya \\ ${ }^{2}$ Department of Environmental Studies, Institute of Graduate Studies and Research, Alexandria University, Egypt \\ ${ }^{3}$ Physiology Department, Faculty of Medicine, Sabratha University, Libya
}

Address for correspondence:

Azab Elsayed Azab, Physiology Department, Faculty of Medicine, Sabratha University, Libya, Email: azabelsaied@yahoo.com

Submitted: 09 May 2020

Approved: 25 May 2020

Published: 27 May 2020

How to cite this article: Shkal KEM, Attia AM, El-Banna SG, Azab AE, Yahya RAM. Anti-dyslipidemic effect of zinc oxide nanoparticles against cyclophosphamide induced dyslipidemia in male albino rats. G Med Sci. 2020; 1(1): 055-063.

https://www.doi.org/10.46766/thegms.pharmaco.20050901

Copyright: ๑ 2020 Azab Elsayed Azab, et al. This is an open access article distributed under the Creative Commons Attribution License, which permits unrestricted use, distribution, and reproduction in any medium, provided the original work is properly cited.

\section{ABSTRACT}

Background: Cyclophosphamide (CP) is used for the treatment of ovarian cancer, breast cancer, chronic lymphocytic leukemia, non-Hodgkin's lymphoma, neuroblastoma, soft tissue sarcoma, rhabdomyosarcoma, and Wilms' tumor. It causes dyslipidemia in experimental animals. Zinc oxide is the most widely used nanoparticles among various nanomaterials. Zinc oxide nanoparticles were ameliorated hepatotoxicity, hematotoxicity oxidative stress, and disturbance in the antioxidant defense system induced by cyclophosphamide in experimental animals.

Objectives: The present study aimed to evaluate the anti-dyslipidemic effect of zinc oxide nanoparticles against cyclophosphamide-induced by dyslipidemia in male albino rats.

Materials and Methods: Twenty-four adult male rats (Sprague Dawley) were grouped randomly into four groups of six rats each. Group I. Control group: Received $0.2 \mathrm{ml}$ saline /day i.p. injection for 14 days (day by day), group II (nZnO group): Received $\mathrm{nZnO}$ ( $5 \mathrm{mg} / \mathrm{kg}$ )/day b.w., intraperitoneally for 14 days, Group III (CP group): Received CP $20 \mathrm{mg} / \mathrm{kg}$ /day body weight (b.w.) day by day for 14 days by intraperitoneal injection, Group IV (CP + ZnO NPs group): Received nZnO group: Received nZnO (5 mg/kg/day) b.w., intraperitoneally for 14 days, plus CP $20 \mathrm{mg} / \mathrm{kg} / \mathrm{day}$ body weight (b.w.) day by day for 14 days by intraperitoneal injection. At the end of the experimental period, rats were anesthetized using light ether. Blood samples were taken and prepared for biochemical measurements.

Results: Administration of CP to rats resulted in a significant increase $(\mathrm{p}<0.05)$ in the levels of serum total cholesterol, triglycerides, and LDLcholesterol and a significant decrease $(\mathrm{p}<0.05)$ in serum HDL-cholesterol, as compared to control group. Conversely, the groups treated with nZnO showed a significant decrease $(\mathrm{p}<0.05)$ in serum total cholesterol, triglycerides, and LDL-cholesterol and a significant increase $(\mathrm{p}<0.05)$ in serum HDL-cholesterol, as compared to CP group.

Conclusion: It can be concluded that exposure of rats to CP induced dyslipidemia and treatment of rats with zinc oxide nano-particles and CP together prevented dyslipidemia induced by CP. These results may provide further visions into the proper treatment of patients by improving the side effects of chemotherapy. However further studies are necessary to establish optimal doses of nZnO and receive the best safety profile.

Keywords: Zinc oxide nanoparticles, Anti-dyslipidemia, Anti-hyperlipidemia, Cyclophosphamide, Lipid profile, Albino rats.

\section{Introduction}

Cyclophosphamide (CP) is a drug used as an anticancer and immunosuppressant agent. CP induces myocardium damage and dyslipidemia [1]. It is used for the treatment of ovarian cancer, breast cancer, chronic lymphocytic leukemia, non-Hodgkin's lymphoma, neuroblastoma, soft tissue sarcoma, rhabdomyosarcoma, and Wilms' tumor [1, 2]. 
CP is activated by hepatic cytochrome P450 mixed-function oxidase system and converted to 4-hydroxycyclophosphamide, which is in equilibrium with aldophosphamide. Aldophosphamide, delivered to both tumour and normal tissue is converted to cytotoxic form phosphoramide mustard and acrolein by non-enzymatically $[1,2]$.

Acrolein damages many cell types by producing reactive oxygen species and lipid peroxidation. Oxidative stress is associated with the pathogenesis of cardiovascular disorder including ischemic heart disease, heart failure, and atherosclerosis. Acrolein also decreases cholesterol clearance by reducing hepatic lipase activity. Reduced cholesterol clearance is associated with dyslipidemia. It induced dyslipidemia is characterized by changes in the lipoprotein composition especially in VLDL cholesterol and triglycerides and induces pro-atherogenic changes in lipoproteins. It was found that, acrolein can induce apoptosis by activation of the mitochondrial pathway or death receptor signaling. In some studies, it was proved that acrolein can exert detrimental effects in adult mice heart tissues through apoptotic cell death $[1,3]$.

CP administration to albino rats caused a significant increase in the levels of total cholesterol, LDL-cholesterol, triglyc eride, and decrease HDL-cholesterol level in the serum compared to the control group [1].

The development of atherosclerosis depends on the balance between pro-inflammatory; anti-inflammatory, and antioxidative defense mechanisms [5]. Vascular proliferation and inflammation are closely linked [6], and excessive proliferation of vascular cells plays an important role in the pathology of vascular occlusive disease. Free radicals are considered to play a casual role in this process [7], and ROS lead to the oxidation of low-density lipoprotein (LDL), and this accumulates within plaques, and contributes to the inflammatory state of atherosclerosis and plays a key role in its pathogenesis [8]. Oxidized-LDL leads to endothelial dysfunction, and can result in either cell growth or apoptotic cell death. Free radicals have also been implicated in congestive heart failure, the annual incidence of which is one to five per 1000 person, and the relative incidence doubles for each decade of life after the age of 45. Experimental evidence suggests a direct link between free radical production and CHF $[9,10]$, and the presence of ROS in circulating blood is also the key intermediary related to vascular injury and organ dysfunction [10-12].

The use of nanoscale materials is growing exponentially as concerns rise about the human hazards to it. It is assumed that living beings are coevolved with nanoparticles ever since the origin of life on earth and therefore, they must have developed the defense and toxicity mitigating mechanisms for nanoparticles. Although having peculiar properties these new materials also present new health risks upon interacting with biological systems. Zinc oxide is the most widely used nanoparticles among various nanomaterials. Recently, these nanoparticles have been shown to specifically kill cancerous cells; therefore, it is believed that these nanoparticles may be used as an alternative anti-tumor agent. However, it is also known that these nanoparticles pose several deleterious effects on living beings [13].

Previous studies reported that zinc oxide nanoparticles were ameliorated hepatotoxicity, hematotoxicity oxidative stress, and disturbance in the antioxidant defense system induced by cyclophosphamide in male albino rats [14-16].

\section{Objectives}

The present study aimed to evaluate the anti-dyslipidemic effect of zinc oxide nanoparticles against cyclophosphamide induced dyslipidemia in male albino rats.

\section{Material and methods}

Experiment was carried out at the Department of Environmental Studies, Institute of Graduate Studies and Research, Alexandria University laboratories.

\subsection{Chemicals}

All reagents were of the highest quality. Zinc oxide as nanoparticles with an average size of $67 \mathrm{~nm}$ is a gift from Dr. Eman El-Trass. Cyclophosphamide (200 mg/ampoule) was purchased from Sigma-Aldrich.

\subsection{Animals}

Twenty four male rats with an average body weight of $150 \pm 30 \mathrm{~g}$ were obtained from the faculty of agriculture, Alexandria University, and acclimatized for two weeks before starting the experiment. The rats were maintained under temperature $(25 \mathrm{oC})$. They were fed with standard food and had free access to water. Animals were randomly divided into 4 groups and housed in Universal galvanized wire cages. 


\subsection{Experimental design}

Adult male rats (Sprague Dawley) were randomly divided into four groups (six rats each) as follows:

Group I. Control group: Received $0.2 \mathrm{ml} /$ day saline i.p. injection for 14 days (day by day).

Group II. nZnO group: Received $\mathrm{nZnO}$ ( $5 \mathrm{mg} / \mathrm{kg} /$ day) b.w., intraperitoneally for 14 days [17].

Group III. CP group: Received CP 20 mg/kg/day body weight (b.w.) (i.p. injection of saline) day by day for 14 days by intraperitoneal injection [18].

Group IV. CP + nZnO group: Received nZnO (5 mg/kg/day) b.w., intraperitoneally for 14 days, plus CP $20 \mathrm{mg} / \mathrm{kg} / \mathrm{day}$ b.w., day by day for 14 days by intraperitoneal injection.

After 24-hr from the last treatments all the animals were anesthetized using light ether. Blood samples were taken from the heart within $1 \mathrm{~min}$. Tubes were used to compile blood drawn from the heart directly; $3 \mathrm{ml}$ was collected in glass tubes for coagulation and serum formation, blood was left for $30 \mathrm{~min}$ at $4^{\circ} \mathrm{C}$ to clot, then centrifuged for 5 minutes at $1000 \mathrm{x}$ g. Packed cells were discarded and the supernatant serum samples were decanted and stored into capped sterile polyethylene tubes at $-20^{\circ} \mathrm{C}$ until used (within 24 hours).

\subsection{Biochemical analysis}

Cholesterol was determined after enzymatic hydrolysis and oxidation according to the method described by Richmond [19]. Triglycerides were determined according to the method described by Carr et al. [20].

LDL Cholesterol test results are based on a reading of light reflected off a test strip that has changed color after blood is applied. The intensity of the color is directly proportional to the concentration of LDL cholesterol in the sample. The analyzer converts this reading into LDL cholesterol result and displays it. This test, which selectively measures LDL cholesterol, is an enzymatic colorimetric test based on the "Trinder Method" for the determination of cholesterol. In the presence of oxygen, cholesterol is oxidized by cholesterol oxidase to cholesterol-4-en-one and hydrogen peroxide. In the presence of peroxidase, hydrogen peroxide reacts with 4-aminoantipyrine and N, Ndisubstituted aniline to form a blue dye [21].

Phossphotungstic acid and magnesium ions selectively precipitating all lipoproteins except the HDL fractioncholesterol present in the supernatant can be determined by the same method used for total cholesterol [22].

\subsection{Statistical Analysis}

Values obtained as Mean \pm SE were subjected to one-way analysis of variance (ANOVA) followed by Tukey test using GraphPad Prism version 5.0 for windows from GraphPad Software, San Diego, California, USA). Values of P <.05 were considered significant.

\section{Results and Discussion}

Administration of CP to rats resulted in a significant increase $(\mathrm{p}<0.05)$ in the levels of serum total cholesterol, triglycerides, and LDL-cholesterol and a significant decrease $(\mathrm{p}<0.05)$ in serum HDL-cholesterol, as compared to control group. Conversely, the groups treated with nZnO showed a significant decrease $(p<0.05)$ in serum total cholesterol, triglycerides, and LDL-cholesterol and a significant increase $(\mathrm{p}<0.05)$ in serum HDL-cholesterol, as compared to CP group (Table 1, Figures 1-4).

Table (1). Effects of treatment of rats with zinc oxide nanoparticles and/or Cyclophosphamide on serum cholesterol, triglycerides, HDL, and LDL.

$\begin{array}{ccccc}\text { Groups } & \text { Control } & \text { nZnO } & \text { CP } & \text { nZnO + CP } \\ \text { Parameters } & \text { Mean } \pm \text { SE } & \text { Mean } \pm \text { SE } & \text { Mean } \pm \text { SE } & \text { Mean } \pm \text { SE }\end{array}$

$\begin{array}{lcccc}\text { Serum Cholesterol }(\mathrm{mg} / \mathrm{dl}) & 52.54 \pm 3.86^{\mathrm{bcd}} & 68.12 \pm 3.81^{\mathrm{ac}} & 83.72 \pm 6.17^{\mathrm{abd}} & 63.72 \pm 3.86^{\mathrm{ac}} \\ \text { Serum Triglycerides }(\mathrm{mg} / \mathrm{dl}) & 62.38 \pm 5.12^{\mathrm{cd}} & 66.46 \pm 4.52^{\mathrm{cd}} & 102.8 \pm 10.04^{\mathrm{abd}} & 80.90 \pm 4.91^{\mathrm{abc}} \\ \text { Serum LDL }(\mathrm{mg} / \mathrm{dl}) & 13.67 \pm 2.05^{\mathrm{bcd}} & 28.56 \pm 2.92^{\mathrm{ad}} & 32.22 \pm 4.91^{\mathrm{ad}} & 18.02 \pm 1.26^{\mathrm{abc}} \\ \text { Serum HDL }(\mathrm{mg} / \mathrm{dl}) & 37.28 \pm 1.44^{\mathrm{bc}} & 29.30 \pm 1.41^{\mathrm{ac}} & 18.50 \pm 7.42^{\text {abd }} & 31.50 \pm 6.10^{\mathrm{c}}\end{array}$

Significance at $P<0.05 .{ }^{\text {a }}$ Comparison of control and other groups; ${ }^{\mathrm{b}}$ Comparison of $\mathrm{nZnO}$ and other groups; ${ }^{\mathrm{c}}$ Comparison of $\mathrm{CP}$ and other groups; ${ }^{\mathrm{d}}$ Comparison of $\mathrm{nZnO}+\mathrm{CP}$ and other groups. 


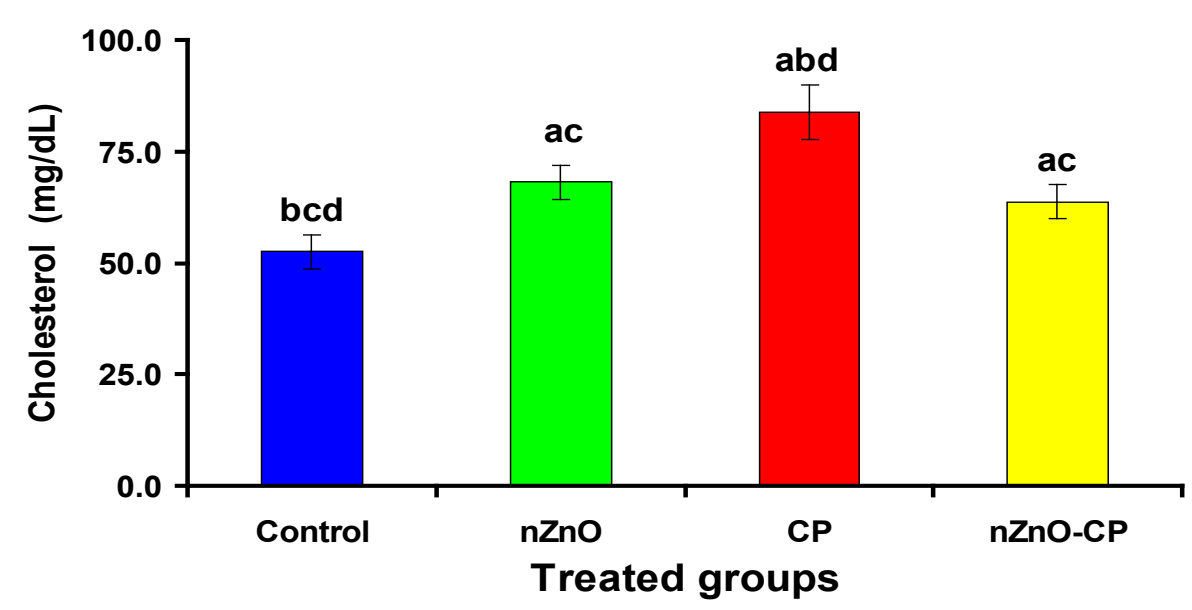

Figure 1: Effects of treatment of rats with zinc oxide nanoparticles and/or cyclophosphamide on serum Cholesterol concentration. Significance at $P<0.05$. ${ }^{\text {a }}$ Comparison of control and other groups; ${ }^{\mathrm{b}}$ Comparison of $\mathrm{nZnO}$ and other groups; ${ }^{\mathrm{c} C o m p a r i s o n}$ of $\mathrm{CP}$ and other groups; ${ }^{\mathrm{d}}$ Comparison of $\mathrm{nZnO}+\mathrm{CP}$ and other groups.

\section{Serum triglyceride}

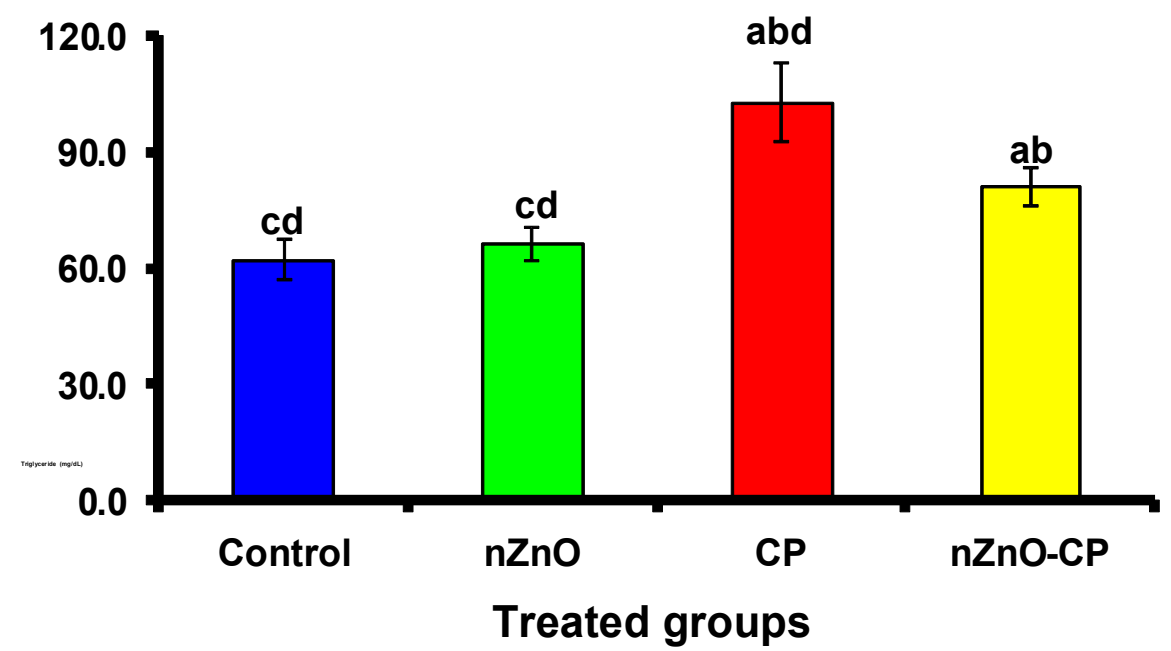

Figure 2: Effects of treatment of rats with zinc oxide nanoparticles and/or cyclophosphamide on serum Triglycerides concentration. Significance at $P<0.05$. ${ }^{a}$ Comparison of control and other groups; ${ }^{\mathrm{b}}$ Comparison of $\mathrm{nZnO}$ and other groups; ${ }^{\mathrm{c}}$ Comparison of $\mathrm{CP}$ and other groups; $\mathrm{d}$ Comparison of $\mathrm{nZnO}+\mathrm{CP}$ and other groups. 


\section{Serum LDL}

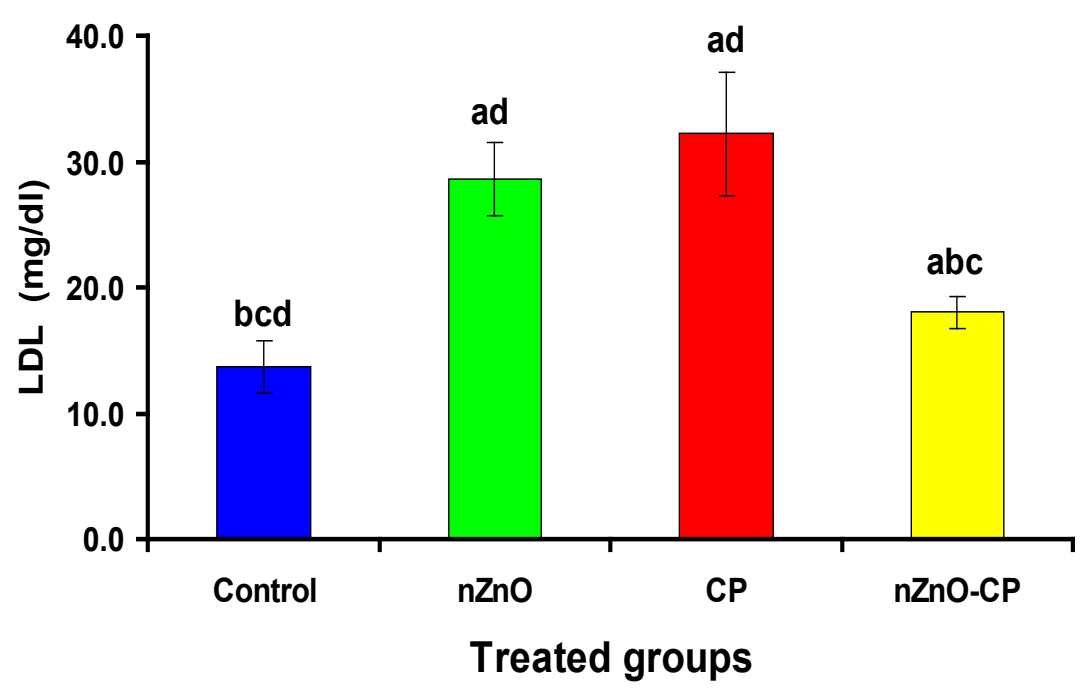

Figure 3: Effects of treatment of rats with zinc oxide nanoparticles and/or cyclophosphamide on serum LDL concentration. Significance at $P<0.05 .{ }^{\text {a }}$ Comparison of control and other groups; ${ }^{\mathrm{b}}$ Comparison of $\mathrm{nZnO}$ and other groups; ${ }^{\mathrm{c}}$ Comparison of $\mathrm{CP}$ and other groups; ${ }^{\mathrm{d}}$ Comparison of $\mathrm{nZnO}+\mathrm{CP}$ and other groups.

Serum HDL

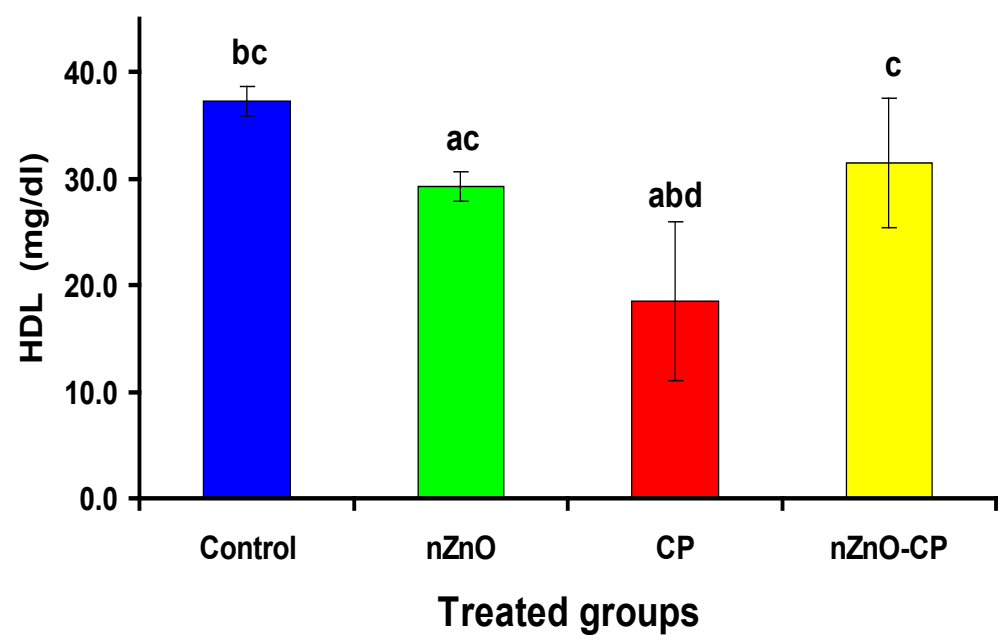

Figure 4: Effects of treatment of rats with zinc oxide nanoparticles and/or cyclophosphamide on serum HDL concentration. Significance at $P<0.05 .{ }^{\text {a }}$ Comparison of control and other groups; ${ }^{\mathrm{b}}$ Comparison of $\mathrm{nZnO}$ and other groups; ${ }^{\mathrm{c} C o m p a r i s o n}$ of $\mathrm{CP}$ and other groups; ${ }^{\mathrm{d}}$ Comparison of $\mathrm{nZnO}+\mathrm{CP}$ and other groups. 
Acute cardiotoxicity such as cardiac decompensation and cardiomyopathy has been associated with high dose cyclophosphamide therapy. The pathogenesis of acute cardiotoxicity may be attributed to an increase in free oxygen radicals in oxazaphosphorine induced cardiotoxicity [23].

Serum lipids and lipoprotein abnormalities are regarded as a highly modifiable risk factor for cardiovascular diseases $[1,24]$. Hypercholesterolemia, hypertriglyceridemia and impaired secretion of heart lipoprotein lipase have been reported in cyclophosphamide treated rabbits $[25,26]$. Perturbation of energy and lipid homeostasis plays a central role in the pathogenesis of heart disease. Primary and/or secondary alterations of lipid metabolism pathways in various conditions lead to myocardial lipid accumulation and lipotoxic cardiomyopathy. Defects in fatty acid uptake, secretion, and oxidation can disrupt myocardial energy and lipid homeostasis [27]. Treatment of cultured vascular smooth muscle cells with free radicals resulted in cholesterol accumulation [28].

The metabolism and physiology of lipids and lipoproteins is a dynamic integrated process. Lipoprotein abnormalities resulting in the disruption of serum and cellular lipid levels account for the genesis of vascular diseases. The acroleinlysine adducts detected in the aorta and plasma LDL of cyclophosphamide treated animals suggest that these adducts wherein acrolein is a metabolite of cyclophosphamide, may play a role in the development of atherosclerosis or atherogenesis [29].

Cyclophosphamide is known to result in hypertriglyceridemia and hypercholesterolemia, which are well-known risk factors in cardiovascular diseases [25].

Cyclophosphamide induces oxidative stress through its toxic metabolite acrolein. It can cause dyslipidemia by increasing cholesterol biosynthesis, decreasing cholesteryl ester hydrolysis, and reducing cholesterol efflux [1, 30, 31]. Cyclophosphamide induces free radicals[32], which may cause cellular cholesterol accumulation, (a) by increasing cholesterol biosynthesis and its esterification, (b) by decreasing cholesteryl ester hydrolysis and (c) by reducing cholesterol efflux $[1,28,30,31]$. The conversion of cholesterol to bile acids is quantitatively the most important mechanism for the degradation of cholesterol. However, McClure and Stupans [33] previously reported that after 7 days following a single dose of cyclophosphamide ( $200 \mathrm{mg} / \mathrm{kg}$ body weight) there was a decrease in cytochrome P450 activity in male rats, which may, in turn, depress cholesterol 7-hydroxylase activity, the key enzyme in the conversion of cholesterol to bile acids.The decline in the cardiac phospholipid content with a concomitant increase in the serum could be due to the peroxidation of unsaturated membrane lipids by free radicals in biomembranes and tissues causing the leakage of these lipids into circulation [34].

Cholesterol and phospholipids are carried in plasma by lipoproteins, which are synthesized and secreted by the intestine and liver. VLDL and HDL are secreted from the liver into the bloodstream. Boren et al. [35] have indicated that cardiac apoB enables the heart to secrete excess lipids in lipoproteins. VLDL is degraded into IDL and LDL by the action of the enzyme LPL and through the exchange reactions with HDL. LDL serves as a major carrier of cholesterol to extrahepatic tissues. High levels of LDL are associated with an increased risk of cardiovascular disease whereas high levels of HDL afford protection by reverse cholesterol transport to the liver. Previously in cyclophosphamide treated rats, lipid composition showed that HDL cholesterol was very low compared to a high VLDL cholesterol [25].

In these animals VLDL was larger than normal, corresponding to triglyceride enrichment [36].

Triglycerides are degraded by the lipoprotein lipase to fatty acids. Alterations in lipoprotein lipase activity induced by cyclophosphamide may increase triglycerides level $[1,30,31]$. Lipoprotein lipase (LPL) is predominantly present in the skeletal muscle, cardiac muscle, and adipose tissue. Defective secretion of LPL may contribute to the poor expression of lipolytic activity in the vascular bed and to the occurrence of hypertriglyceridemia during cyclophosphamide treatment. Simultaneously heart LPL activity was also decreased in fasted animals [37]. Due to the alterations in LPL activity, an increase in triglycerides was associated with a drop in fatty acid levels in the heart of group II cyclophosphamide treated rats. The moderate increase in the rate of triacylglycerol synthesis by the liver contributes to the occurrence of hypertriglyceridaemia in cyclophosphamide treated rats [37]. Hypercholesterolemic changes in these rats may be explained by a marked reduction in the activities of fat splitting enzymes, such as plasma LCAT and cardiac LPL. LCAT is secreted by the hepatocytes and released into the plasma. It converts cholesterol into long-chain cholesteryl ester on HDL and favours reverse cholesterol transport from tissues to the liver. The esterification of cholesterol by LCAT leads to the remodeling of the lipoprotein HDL, and results in the formation of large HDL particles that are known to offer protection against coronary artery disease [38]. Cholesterol esterification in the tissue is reported to be mediated through cholesterol ester Synthetase.

The present study proved that treatment of the CP-treated rats with ZnONPs prevented changes in serum lipids profile; this may be due to the antioxidant characters of ZnONPs [39]. It is well known that $\mathrm{Zn}$ is a powerful antioxidant metal; it is the core constituent of antioxidant enzymes such as SOD and a recognized protector of sulfhydryl groups; it is also thought to impair lipid peroxidation by displacing transition metals such as iron and copper from catalytic sites [40]. $\mathrm{nZnO}$ can protect cell membrane integrity against oxidative stress damage, increase antioxidant enzyme levels, and decrease MDA level. It can improve antioxidant activity, enhance the activities of antioxidases, and decrease the levels of free radicals [41]. The authors concluded that zinc oxide nanoparticles improved the lipid profile when it administered in combination with CP. 


\section{Conclusion}

It can be concluded that exposure of rats to CP induced dyslipidemia and treatment of rats with zinc oxide nanoparticles and CP together prevented dyslipidemia induced by CP. These results may provide further visions into the proper treatment of patients by improving the side effects of chemotherapy. However further studies are necessary to establish optimal doses of $\mathrm{nZnO}$ and receive the best safety profile.

\section{References}

1. Das R, Devi KS, Dutta S, Das A, Das P, and Devi KKP. (2017). Effects of Ipomoea aquatica Forsk. in cyclophosphamide induced dyslipidaemia in albino rats. Int J Basic Clin Pharmacol., 6(11): 2743-2748.

2. Chu E, and Sartorelli AC. (2015). Cancer chemotherapy. In: Katzung BG, Trevor AJ, editors. Basic and clinical pharmacology. $13^{\text {th }}$ Ed. New Delhi: McGraw-Hill Education. PP. 918-945.

3. Conklin DJ, Barski OA, Lesgards JF, Juvan P, Rezen T, Rozman D, et al. (2010). Acrolein consumption induces systemic dyslipidemia and lipoprotein modification. Toxicol Appl Pharmacol., 243(1): 1-26.

4. Taghiabadi E, Imenshahidi M, Abnous K, Mosafa F, Sankian M, Bahram Memar B, et al. (2012). Protective effect of silymarin against acrolein-induced cardiotoxicity in mice. Evid Based Complement Alternat Med., 2012: 1-14.

5. Scott, J. (2004). Pathophysiology and biochemistry of cardiovascular disease. Curr. Opion. Genet. Develop., 14:271279.

6. Dzau, V.J., Braun-Dullaeus, R.C. and Sedding, D.G. (2002). Vascular proliferation and atherosclerosis: new perspectives and therapeutic strategies. Nat. Ned., 8:1249-1256.

7. Schachinger, V., Zeiher, A.M. (2002). Atherogenesis-recent insights into basic mechanisms and their clinical impact. Nephrol Dial Transplant., 17:2055-2064.

8. Galle, J., Hansen-Hagge, T., Wanner, C. and Seibold, S. (2006). Impact of oxidized low density lipoprotein on vascular cells. Atherosclerosis., 185: 219-226.

9. Mariani E, Polidori MC, Cherubini A, et al. (2005). Oxidative stress in brain aging, neuro- degenerative and vascular diseases: An overview. J Chromat B, 827:65-75.

10. Rahman, K. (2007). Studies on free radicals, antioxidants, and co-factors. Clinical interventions in aging, 2(2): 219236.

11. Fukai T, Folz RJ, Landmesser U, et al. (2002). Extracellular superoxide dismutase and cardiovascular disease. Cardiovasc Res, 55:239-249.

12. Elahi MM, Matata BM. (2006). Free radicals in blood: Evolving concepts in the mechanism of ischemic heart disease. Arch Biochem Biophys, 450: 78-88.

13. Roy, R., Das, M. and Dwivedi, P.D. (2015). Toxicological mode of action of ZnO nanoparticles: Impact on immune cells. Mole Immunol., 63(2): 184-192.

14. Shkal KEM, Attia AM, El-Banna SG, Azab AE, and Yahya RAM. (2020). Ameliorating effect of zinc oxide nanoparticles against hematotoxicity induced by cyclophosphamide in male albino rats. Advan Hematol Oncol Res., 3(1): 26-31.

15. Shkal KEM, Attia AM, El-Banna SG, Azab AE, and Yahya RAM. (2020). Zinc oxide nanoparticles alleviate cyclophosphamide induced hepatotoxicity in male albino rats. Advan Nanosci Nanotechnol., 4(2): 1-7.

16. Shkal KEM, Azab AE, Attia AM, El-Banna SG, and Yahya RAM. (2020). Zinc oxide nanoparticles attenuate the oxidative damage and disturbance in antioxidant defense system induced by cyclophosphamide in male albino rats. Insights Biol Med. In Press.

17. Badkoobeh, P., Parivar, K., Kalantar, S.M., Hosseini, S.D., and Salabat, A. (2013). Effect of nano-zinc oxide on doxorubicin- induced oxidative stress and sperm disorders in adult male Wistar rats. Iran J Reprod Med., 11(5): 355-364.

18. Fahmey, M.A., Hassan, N.H.A., El-Fiky, S.A., and Elalfy, H.G. (2015). A mixture of honey b Fahmy, M.A., Hassan, N.H.A., El-Fiky, S.A. and Elalfy, H.G. (2015). A mixture of honey bee products ameliorates the genotoxic side effects of cyclophosphamide. Asian Pacific J Trop Dis., 5(8): 638-644. 
19. Richmond, W. (1973). Preparation and properties of a cholesterol oxidase from Nocradia sp. and its application to the enzymatic assay to total cholesterol in serum. Clin. Chem., 18: 1350.

20. Carr, T., Andressen, C.J. and Rudel, L.L. (1993). Enzymatic determination of triglyceride, free cholesterol and total cholesterol in tissue lipid extracts. Clin. Chem., 26: 39-42.

21. Assmann, G., Jabs, H.U., Kohnert, U., Nolte, W. and Schriewer, H. (1984). LDL- cholesterol determination in blood serum following precipitation of LDL with polyvinylsulfate. Clin. Chem. Acta., 140: 77-83.

22. Burstein, M., Scholnick, H.R. and Morfin, R. (1980). Rapid method for the isolation of lipoproteins from human serum by precipitation with polyanions. Scand J. Clin. Lab. Invest., 40: 583-595.

23. Schimmel, K.J., Richel, D.J., Van den Brink, R.B. and Guchelaar, H.J. (2004). Cardiotoxicity of cytotoxic drugs. Cancer Treat. Rev. 30: 181-191.

24. Bersot TP. (2011). Drug therapy for hypercholesterolemia and dyslipidemia. In: Brunton LL, Chabner BA, Knollmann BC, editors. Goodman and Gilman's The Pharmacological Basis of Therapeutics. $12^{\text {th }}$ Ed. New York: McGrawHill Medical. PP. 877-908.

25. Loudet, A.M., Dousset, N., Carton, M. and Douste-Blazy, L. (1984). Effects of an antimitotic agent (cyclophosphamide) on plasma lipoproteins. Biochem. Pharmacol. 33: 2961-2965.

26. Lespine, A., Chap, H. and Perret, B., (1997). Impaired secretion of heart lipoprotein lipase in cyclophosphamidetreated rabbit. Biochim. Biophys. Acta 1345: 77-85.

27. Yang, Q. and Cheng, L., (2005). Molecular regulation of lipotoxicity in the heart. Drug Discov. Today: Dis. Mech. 2: 101-107.

28. Gesquiere, L., Loreau, N., Minnich, A., Davignon, J. and Blache, D., (1999). Oxidative stress leads to cholesterol accumulation in vascular smooth muscle cells. Free Radic. Biol. Med. 27: 134-145.

29. Arikketh, D., Niranjali, S. and Devaraj, H. (2004). Detection of acrolein-lysine adducts in plasma low-density lipoprotein and in aorta of cyclophosphamide-administered rats. Arch. Toxicol., 78: 397-401.

30. Gado AM, Adam ANI, and Aldahmash BA. (2013). Cardiotoxicity induced by cyclophosphamide in rats: protective effect of curcumin. J Res Environ Sci Toxicol., 2(4): 87-95.

31. Swamy AHMV, Patel UMP, Koti BC, Gadad PC, Patel NL, and Thippeswamy AHM. (2013). Cardioprotective effect of Saraca indica against cyclophosphamide induced cardiotoxicity in rats: a biochemical, electrocardiographic and histopathological study. Indian J Pharmacol., 45(1) :44-48.

32. Lee, C.K., Harman, G.S., Hohl, R.J. and Gingrich, R.D. (1996). Fatal cyclophosphamide cardiomyopathy: its clinical course and treatment. Bone Marrow Transplant., 18: 573-577.

33. McClure, M.T. and Stupans, I. (1992). Investigation of the mechanism by which cyclophosphamide alters cytochrome P450 in male rats. Biochem. Pharmacol., 43: 2655-2658.

34. Muralikrishnan, G., Amalan Stanley, V. and Pillai, K. (2001). Dual role of vitamin C on lipid profile and combined application of cyclophosphamide,methotrexate and 5-fluorouracil treatment in fibrosarcoma-bearing rats. Cancer Lett., 169: 115-120.

35. Boren, J., Veniant, M.M. and Young, S.G. (1998). Apo B100-containing lipoproteins are secreted by the heart. J. Clin. Invest., 101: 1197-1202.

36. Lespine, A., Dousset, N., Perret, B., De Forni, M., Chap, H. and Douste-Blazy, L., (1988). Accumulation of large VLDL in cyclophosphamide treated rabbits. Relationship with lipoprotein lipase deficiency. Biochem. Biophys. Res. Commun., 154: 633-640.

37. Lespine, A., Azema, C., Gafvels, M., Manent, J., Dousset, N., Chap, H. and Perret, B. (1993). Lipoprotein lipase regulation in the cyclophosphamide-treated rabbit: dependence on nutritional status. J. Lipid Res., 34: 23-36.

38. Subramanian, R., Ramaswamy, M. and Wasan, K.M., (2003). Role of lipid and lipoprotein metabolizing enzymes in the development of atherosclerosis. Indian J. Exp. Biol., 41: 14-25.

39. Afifi, M. and Abdelazim, A.M. (2015). Ameliorative effect of zinc oxide and silver nanoparticles on antioxidant system in the brain of diabetic rats, Asian Pacific Journal of Tropical Biomedicine, 5(10): 874-877.

40. Aitken, R.J. and Roman, S. D. (2008). Antioxidant systems and oxidative stress in the testes. Oxidative Medicine and Cellular Longevity, 1(1): 15-24. 
41. Badkoobeh, P., Parivar, K., Kalantar, S.M., Hosseini, S.D. and Salabat, A. (2013). Effect of nano-zinc oxide on doxorubicin-induced oxidative stress and sperm disorders in adult male Wistar rats. Iranian Journal of Reproductive Medicine, 11(5): 355-364. 